\title{
A controlled, longitudinal study of dementia in Parkinson's disease
}

C Anthony Biggins, Jane L Boyd, Francesca M Harrop, Peter Madeley, Richard H S Mindham, Jill I Randall, Ernest G S Spokes

\begin{abstract}
Serial assessments of cognition, mood, and disability were carried out at nine month intervals over a 54 month period on a cohort of 87 patients with Parkinson's disease (PD) and a matched cohort of 50 control subjects. Dementia was diagnosed from data by rigorously applying DSMIII-R criteria. Initially, $6 \%$ (5/87) PD patients were demented, compared with none of the 50 control subjects. A further 10 PD patients met the dementia criteria during the follow up period; this was equivalent, with survival analysis, to a cumulative incidence of $19 \%$. With the number of person years of observation as the denominator, the incidence was $47 \cdot 6 / 1000$ person years of observation. None of the control subjects fulfilled dementia criteria during the follow up period. The patients with PD who became demented during follow up were older at onset of Parkinson's disease than patients who did not become demented, had a longer duration of Parkinson's disease, and were older at inclusion to the study.
\end{abstract}

Estimates of the prevalence of dementia in Parkinson's disease (PD) have varied widely and range from $0 \%$ to $81 \% .^{12}$ Brown and Marsden have argued convincingly that this variation is due to methodological inconsistencies between studies. ${ }^{3}$ Much of the inconsistency has resulted from the use of a variety of definitions and methods of identifying dementia. The use of standard criteria for diagnosis of dementia has improved consistency in reported prevalence; for example, studies using DSM-III criteria ${ }^{4}$ report prevalences between $11 \%$ and $15 \% .^{5-7}$

A further difficulty relates to study design. Virtually all studies that have examined dementia in PD have been either retrospective reviews of case notes, which depend on the quality of the case notes, or single cross sectional assessments, which pose problems of interpretation. Poor performance on cognitive testing on a single occasion could result from factors other than dementia, such as the effects of medication or mood disturbance. In addition, some patients perform badly on cognitive testing as a result of low premorbid intelligence rather than a decline due to dementia. Some investigators have attempted to provide evidence of decline by showing a discrepancy between estimates of premorbid intelligence and current intelligence. ${ }^{89}$ This is only an indirect way of showing decline and, because no instrument for estimating premorbid intelligence has yet been validated for use in PD, results may be misleading.

Serial assessments of patients can overcome these difficulties. Firstly, poor performance on cognitive testing on a single occasion may be seen to be transient, in which case dementia is unlikely to be the cause. Secondly, decline can be directly observed rather than inferred from the use of unvalidated tests of premorbid intelligence. Thirdly, cross sectional assessment can give only an estimate of prevalence of dementia in PD but serial assessments can enable the incidence of dementia to be estimated and may provide information about the evolution and prognosis of dementia in PD.

Mayeux et al recently estimated the incidence of dementia in PD. ${ }^{10}$ They rightly emphasised that incidence is a better indicator than prevalence of the occurrence of dementia in PD: if coincident PD and dementia result in a greater mortality than PD uncomplicated by dementia the prevalence of dementia in PD will be lowered. Their study, however, is flawed for several reasons. Firstly, their data are derived from a retrospective review of case notes (supplemented in some cases by telephone interview of an informant) rather than from prospective, standardised testing using clinical or neuropsychological instruments. Secondly, they have not directly compared a control group by using the same methods. And thirdly, as their diagnosis of DSM-III dementia was not made blind (to whether subjects had PD or not) it may have been subject to observer bias. The reliability of their method of diagnosis of dementia was not formally examined, but the revision of their previously quoted prevalence in the same patient sample from $10.9 \%^{5}$ to $15.9 \%$ reflects the limitations of their methodology. As these authors acknowledge, a prospective investigation is required to examine more accurately the incidence of dementia in PD.

We carried out longitudinal assessments of cognition, mood, and disability at nine month intervals over a 54 month follow up period on a cohort of patients with PD and a matched cohort of control subjects. On the basis of the data we judged whether DSM-III-R dementia was present in each subject and, if present, when it occurred. We present our findings in the form of a survival analysis.

\section{Patients and method}

Subjects

Most patients included in the study came from 
a single local neurological clinic (at Leeds General Infirmary). These comprised all existing patients and consecutive new referrals with a diagnosis of idiopathic PD. None refused to take part in the study. A few patients were volunteers from other local neurological clinics. Patients were seen by members of the research team; they were considered suitable for inclusion to the study if they had at least two of the three major features of PD (rigidity, tremor, and bradykinesia), a history of insidious onset and progression of symptoms, and none of the following exclusion criteria: 1) history of stroke, transient ischaemic attack, hypertension, syphilis, encephalitis, epilepsy, cerebral tumour, alcoholism, diabetes mellitus, or head injury resulting in loss of consciousness; 2) presence or history of any neurological sign not compatible with a diagnosis of $\mathrm{PD}$ (such as cerebellar signs, supranuclear gaze palsy, oculogyric crises); 3) presence and any illness associated with chronic confusional states or of any chronic disabling disease other than PD; 4) surgery in the past six months or neuroleptic drugs in the past three months. Healthy control subjects, individually matched for age and sex to the first 50 PD patients, were recruited from spouses and other relatives of patients or from general practice or a local day centre for the elderly.

\section{Assessment}

Neurological examination consisted of Hoehn and Yahr's staging for PD, ${ }^{11}$ Webster's scale, ${ }^{12}$ and Northwestern Universities Disability Scale $(\text { NUDS })^{13}$. Psychiatric assessment consisted of the administration of the MontgomeryÅsberg Depression Rating Scale (MADRS) ${ }^{14}$ and the Mini Mental State Examination (MMSE). ${ }^{15}$ The neuropsychological testing comprised the verbal scale and picture completion subtest of the Weschler Adult Intelligence Scale (WAIS), ${ }^{16}$ the logical memory and associated learning subtests of the Weschler Memory Scale (WMS), ${ }^{17}$ and the Graded Naming Test (GNT). ${ }^{18}$ The National Adult Reading Test (NART) ${ }^{19}$ was administered at the first assessment only. The rationale for the use of these tests has been fully discussed elsewhere. $^{20}$

Subjects were assessed, according to their preference, in their own homes or in the research office in the department of psychiatry; almost all were assessed at home. The testing took 90-120 minutes to complete. Subjects were assessed at nine month intervals from the initial assessment. The diagnosis of idiopathic PD was reviewed on each occasion. For the purposes of this presentation, only data collected up to the "closing date" of 31 August 1990 were used, although the assessment of subjects continues.

\section{Identification of dementia}

No diagnoses of dementia were made until after the "closing date" of 31 August 1990, when data were examined. DSM-III-R criteria for the diagnosis of dementia were used. ${ }^{21}$ (The dementia criteria of DSM-III-R are virtually identical to those of DSM-III). For such a diagnosis to be made there must have been impairment of short and long term memory (criterion A) and also impairment of at least one other area of "higher cortical function" (criterion B). Examples given include: impaired abstract memory, impaired judgment, aphasia, apraxia, agnosia, constructional difficulty, and personality change. Criteria $A$ and $B$ therefore identified subjects who had possible dementia on the basis of formal cognitive testing, although little guidance has been given as to what tests should be used and what constitutes "impairment." The remaining criteria require that "the disturbance" (as defined by criteria A and B) interferes significantly with occupational or social functioning (criterion $\mathrm{C}$ ), that it is not due solely to delirium (criterion $\mathrm{D}$ ), and that either an aetiological organic factor can be implicated or that the disturbance is not due to non-organic mental illness (criterion E). Thus criteria C, D, and $E$ need subjective judgments to be made on the basis of unquantifiable but detailed knowledge of the subject in order to confirm or refute the diagnosis of dementia. We have therefore applied DSM-III-R dementia criteria as follows.

For each subject a data summary sheet was prepared. Each sheet contained the data obtained from each of the serial assessments made on a given subject on the following tests: seven WAIS subtests (the six from the verbal scale and the picture completion subtest), the logical memory and associate learning subtests of the WMS, the NART, the MMSE and the GNT. All the available data for each subject were displayed on a single sheet. Data were arranged on each sheet so that all the results for an assessment were represented as a row of data (with the initial assessment comprising the top row, and subsequent assessments forming successive rows below). Results for each test thus formed columns, allowing easy comparison of test performances between assessments in a given individual. This arrangement facilitated the identification of subjects whose test performance deteriorated progressively. Subjects showing deterioration on tests at one or more visits but with subsequent recovery on further assessment were unlikely to be mistakenly identified as demented.

Two independent raters were each given the data summary sheets for all subjects in the study along with a copy of the DSM-III-R diagnostic criteria. Both rathers were experienced clinicians but from different disciplines: one was a psychiatrist and the other a clinical psychologist. The data sheets were prepared in such a way that the raters were blind as to which subjects were PD patients and which were control subjects. The raters were required to decide on the basis of the data whether each subject met both criterion $A$ and criterion $B$ (as a forced choice task) and if so at which assessment these criteria were first met. The raters were also invited to write down any comments they had for each subject. Subjects identified by these blind raters as meeting criteria $A$ and $B$ were further evaluated by two 
Table 1 A comparison of patients with Parkinson's disease and control subjects at inclusion in the study

\begin{tabular}{|c|c|c|}
\hline 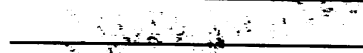 & $P D$ patients $(n=87)$, Cojtrol subjects $(n=50)$ & p Value \\
\hline $\begin{array}{l}\text { Sex M;F: } \\
\text { Mean (SD) age } \\
\text { Mean (SD) NFSIQ } \\
\text { Mean (SD) WAISVIQ } \\
\text { Median (range) MADRS score }\end{array}$ & $\begin{array}{cc}55: 32 & 33: 17 \\
64: 1(10.1) & 64.4(9 \cdot 8) \\
10.9(8-3) & 112.2(8 \cdot 7) \\
105.8(10: 2) & 110.7(11 \cdot 4) \\
5.0(0-29) & \because 4.0(0-16)\end{array}$ & $\begin{array}{l}0.886 \\
0.397 \\
0.015^{\star} \\
0.004^{\star} \dagger\end{array}$ \\
\hline
\end{tabular}

Table 2 Blind rating of DSA $-I I I-R$ dementia critoria by two independent raters using

\begin{tabular}{|c|c|c|c|c|}
\hline & & Rater 2 & & \\
\hline$\dot{5}$ & $=8$ & $\begin{array}{l}\text { Meet criteria } \\
A-\text { and } B\end{array}$ & $\begin{array}{l}\text { Do not meet } \\
\text { criteria } A \text { and } B\end{array}$ & Total \\
\hline Rat & Meet criteria A and B & 10 & 4 & 14 \\
\hline . & Do not meet criteria $A$ and $B$ & 5 & 118 & 123 \\
\hline Total & & 15 & 122 & 137 \\
\hline
\end{tabular}

psychiatrists (CAB and PM) who had carried out the assessments and knew the subjects well. "These two psychiatrists, if satisfied that the identified subjects did meet criteria $A$ and $B$, then applied the remaining criteria $(C, D$, and $\mathrm{E}_{\text {) }}$.

\section{Survival analysis}

The first assessment at inclusion into the study was regarded as the "initial event" and the onset of DSM-III-R dementia as the "terminal event." The survival and other statistical analyses were carried out using the SPSS-X statistical package. ${ }^{22}$

\section{Results}

A total of 91 patients with PD was recruited between June 1985 and September 1989, and 50 control subjects were recruited between June 1985 and December 1987. This report is based on data obtainet up to 31 August 1990. Four PD patients were excluded from the analyses because during follow up the initial diagnosis of PD could not be sustained (two had progressive supranuclear palsy, one developed motor neuron disease, one was found on revièw to have suffered severe head injury

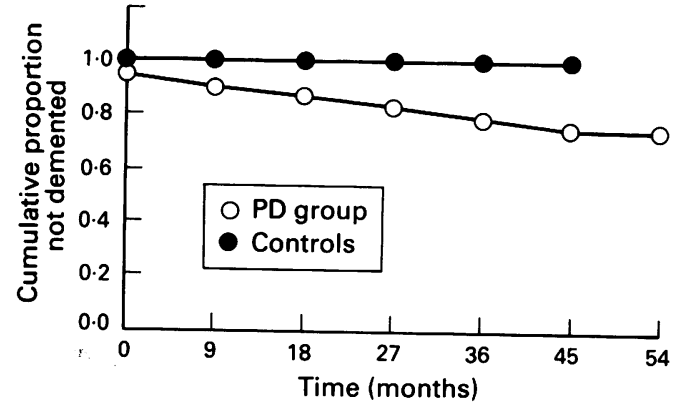

Figure Cumulative proportion of Parkinson's disease patients (open circles) and control subjects (closed circles) not meeting dementia criteria.

before onset of symptoms and symptoms did not progress). Of the 87 PD patients remaining, 69 were from a neurology outpatient clinic run by one of us (EGSS); 18 PD patients were referred by five other neurologists. No significant differences in age, sex, or premorbid intelligence were found between patients and control subjects at first assessment (table 1). The PD cohort, however, had. lower mean WAIS verbal IQs and higher MADRS scores. Follow up ranged from 0-60 (median 37) months in PD patients and 0-52 (38) months in control subjects.

\section{Survival analysis}

Nineteen subjects were selected by at least one rater as meeting DSM-III-R dementia criteria $A$ and B (table 2); none of these were control subjects. The two psychiatrists who had tested the subjects, satisifed that all 19 did meet criteria A and B, applied criteria C, D, and E; three patients failed to meet criterion $\mathrm{C}$ and one failed to meet criterion $\mathrm{E}$ (owing to depressive illness). Thus 15 patients met DSM-III-R criteria for dementia. Survival time was calculated as the time from the first assessment to the assessment at which subjects first met the dementia criteria. Five of 87 patients $(6 \%)$ were considered to be demented on the first assessment, and 10 became demented during the follow up period. The results of the survival analysis are shown in table 3 and figure 1. The cumulative proportion of PD patients surviving (that is, who did not become demented) at the end of 54 months was $75 \%(0 \cdot 75)$. The cumulative incidence of dementia during the follow up period is therefore $19 \%$ ( $25 \%$ minus $6 \%$ ). With the

Table 3 Survival tables for Parkinson's disease patients and control subjects. Terminal event occurs when a subject meets DSM-III-R criteria for dementia; survival is, therefore, failure to meet dementia criteria

\begin{tabular}{|c|c|c|c|c|c|c|}
\hline & $\begin{array}{l}\text { Time from initial } \\
\text { assessment } \\
\text { (months) }\end{array}$ & $\begin{array}{l}\text { No of subjects } \\
\text { entering interval }\end{array}$ & $\begin{array}{l}\text { No of subjects } \\
\text { withdrawn * in } \\
\text { interval }\end{array}$ & $\begin{array}{l}\text { No of terminal } \\
\text { events }\end{array}$ & $\begin{array}{l}\text { Proportion } \\
\text { terminating }\end{array}$ & $\begin{array}{l}\text { Cumulative } \\
\text { proportion } \\
\text { surviving at end }\end{array}$ \\
\hline PD patients & $\begin{array}{r}0 \\
9 \\
18 \\
27 \\
36 \\
45 \\
\geqslant 54\end{array}$ & $\begin{array}{l}87 \\
70 \\
60 \\
52 \\
44 \\
30 \\
14\end{array}$ & $\begin{array}{r}12 \\
7 \\
6 \\
6 \\
12 \\
15 \\
14\end{array}$ & $\begin{array}{l}5 \\
3 \\
2 \\
2 \\
2 \\
1 \\
0\end{array}$ & $\begin{array}{l}0.062 \\
0.045 \\
0.035 \\
0.041 \\
0.053 \\
0.044 \\
0.000\end{array}$ & $\begin{array}{l}0.938 \\
0.896 \\
0 \cdot 864 \\
0 \cdot 829 \\
0.786 \\
0.751 \\
0.751\end{array}$ \\
\hline Control subjects & $\begin{array}{r}0 \\
9 \\
18 \\
27 \\
36 \\
\geqslant 45\end{array}$ & $\begin{array}{l}50 \\
42 \\
40 \\
37 \\
32 \\
12\end{array}$ & $\begin{array}{r}8 \\
2 \\
3 \\
5 \\
20 \\
12\end{array}$ & $\begin{array}{l}0 \\
0 \\
0 \\
0 \\
0 \\
0\end{array}$ & $\begin{array}{l}0.000 \\
0.000 \\
0.000 \\
0.000 \\
0.000 \\
0.000\end{array}$ & $\begin{array}{l}1.000 \\
1.000 \\
1.000 \\
1.000 \\
1.000 \\
1.000\end{array}$ \\
\hline
\end{tabular}

ॠIncludes subjects dropping out of study, and subjects not in study long enough to reach next interval. 
Table 4 Details of subject withdrawal during study. Includes subjects who withdrew after terminal event

\begin{tabular}{lllll}
\hline \multirow{2}{*}{$\begin{array}{l}\text { No of assessments completed } \\
\text { (months in study) }\end{array}$} & \multicolumn{2}{l}{ No of subjects withdrawing } & $\begin{array}{c}\text { Total (\% of } \\
\text { initial cohort }\end{array}$ \\
\cline { 2 - 5 } & Death & Refusal & Other & \\
\hline PD patients & & & & $12(14 \%)$ \\
$1(0)$ & 5 & 6 & 1 & $7(8 \%)$ \\
$2(9)$ & 3 & 4 & 0 & $4(5 \%)$ \\
$3(18)$ & 3 & 1 & 0 & $1(1 \%)$ \\
$4(27)$ & 2 & 2 & 0 & 0 \\
$5(36)$ & 1 & 0 & 0 & $1(1 \%)$ \\
$6(45)$ & 0 & 0 & 0 & $29(33 \%)$ \\
$7(54)$ & 1 & 0 & 0 & $8(16 \%)$ \\
Withdrawn at any time & 15 & 13 & 1 & $2(4 \%)$ \\
Control subjects & & & & $3(6 \%)$ \\
$1(0)$ & 2 & 4 & 2 & $3(6 \%)$ \\
$2(9)$ & 0 & 2 & 0 & $1(2 \%)$ \\
$3(18)$ & 2 & 1 & 0 & 0 \\
$4(27)$ & 0 & 1 & 2 & $17(34 \%)$ \\
$5(36)$ & 0 & 1 & 0 & \\
$6(45)$ & 0 & 0 & 0 & 4 \\
Withdrawn at any time & 4 & 9 & 4 & \\
\hline
\end{tabular}

number of person years of follow up as the denominator, the incidence is calculated to be $47 \cdot 6 / 1000$ person years of observation.

\section{Subject attrition}

Some subjects withdrew from the study after recruitment and initial assessment, mostly before reaching the terminal event (dementia). Subjects withdrew for three main reasons: death; refusal to be tested further; or moving away to another part of the country. The withdrawal of subjects at different times in the study is summarised in table 4 . The highest attrition rate occurred between first and second assessments in both cohorts, with the PD cohort losing 12 (14\%) subjects and the control cohort losing 8 (16\%). In all, $33 \%$ of the PD cohort (29 patients) and $34 \%$ of the control cohort (17 subjects) was lost. Of the 29 PD patients who withdrew from the study, six had already reached the terminal event before withdrawing.

For both cohorts, findings at inclusion to the study were compared between those who withdrew before reaching the terminal events and those who remained in the study (table 5). Among PD patients, those who withdrew were older and scored higher on the disability measure (NUDS); showed a trend towards more severe PD as measured by the Hoehn and Yahr and Webster scales, although differences were not statistically significant; and had no differences in scores on the WAIS verbal scale, NART, or MADRS. Among control subjects, those who withdrew were older and had lower NART performances. The mean
WAIS verbal IQ of the control subjects who withdrew was lower than that of the control subjects who remained, but this difference was not significant.

Comparison of demented and non-demented PD patients

To determine whether we can predict which PD patients become demented, we compared the findings on initial assessment in the following two groups. Group 1 consisted of the 10 PD patients who were not demented at the first assessment but subsequently met dementia criteria during the follow up period. Group 2 consisted of the 41 PD patients who were observed for at least 36 months without onset of dementia (table 6). Those who subsequently developed dementia were older, had a longer duration of PD, had an older age at onset of $P D$, and had low initial performances on the verbal scale of the WAIS and on the MMSE. Premorbid intelligence as predicted by the NART was not significantly different in the two groups. Among those who became demented there was a trend towards more severe PD, but the differences on the Hoehn and Yahr, Webster, and NUDS measures did not reach significance. Of the 10 patients who became demented, only one was female, and in the 41 patients who did not become demented, 17 were female $\left(\chi^{2}=3 \cdot 48, \mathrm{df}=1, \mathrm{p}=0.06\right)$.

\section{Discussion}

In a cohort of 82 non-demented PD patients, 10 became demented during the follow up period. On survival analysis this is equivalent to an incidence of dementia of $19 \%$ in our cohort over the 54 months of observation. None of the control subjects became demented.

Two issues relating to the sample of $\mathrm{PD}$ patients need to be considered. Firstly, did our patients have idiopathic PD? No currently available criteria are entirely satisfactory for diagnosing Parkinson's disease as opposed to Parkinsonism. ${ }^{23}$ Possibly the most stringent criteria available are those adopted by the UK Parkinson's Disease Society Brain Bank. ${ }^{24}$ These, however, were not available in 1985 when this study was initiated. Our criteria, though admittedly less exhaustive than those of the brain bank, incorporate many of the same stipulations. All of our PD patients meet the brain bank criteria when applied retro-

Table 5 First assessment data compared according to whether or not subjects withdrew from study (without meeting dementia criteria)

\begin{tabular}{|c|c|c|c|c|c|c|}
\hline \multirow[b]{2}{*}{$N$} & \multicolumn{3}{|l|}{$P D$ patients } & \multicolumn{3}{|l|}{ Control subjects } \\
\hline & $\begin{array}{l}\text { Not withdrawn } \\
(n=64)\end{array}$ & $\begin{array}{l}\text { Withdrawn } \\
(n=23)\end{array}$ & p Value & $\begin{array}{l}\text { Not withdrawn } \\
(n=33)\end{array}$ & $\begin{array}{l}\text { Withdrawn } \\
(n=17)\end{array}$ & p Value \\
\hline $\begin{array}{l}\text { Mean (SD) age (years) } \\
\text { Mean (SD) WAISVIQ } \\
\text { Mean (SD) NFSIQ } \\
\text { Median (range) MADRS } \\
\text { Median (range) Hoehn and Yahr staging } \\
\text { Median (range) Webster's rating } \\
\text { Median (range) NUDS }\end{array}$ & $\begin{aligned} & 62 \cdot 6(10 \cdot 2) \\
& 106 \cdot 6(10 \cdot 0) \\
& 110 \cdot 8(8 \cdot 4) \\
& 5(0-23) \\
& 3(1-4) \\
& 10(2-24) \\
& 43(15-50)\end{aligned}$ & $\begin{array}{l}68 \cdot 3(8 \cdot 6) \\
103 \cdot 5(10 \cdot 8) \\
109 \cdot 9(8 \cdot 6) \\
4(1-29) \\
3(1-5) \\
11(3-23) \\
35 \cdot 5(26-48)\end{array}$ & $\begin{array}{l}0.013^{\star} \\
0.244 \\
0.652 \\
0.783 \\
0 \cdot 187 \\
0 \cdot 215 \\
0.011^{\star}\end{array}$ & $\begin{array}{c}62 \cdot 3(10 \cdot 3) \\
112 \cdot 5(9 \cdot 7) \\
114 \cdot 5(7 \cdot 2) \\
4(0-11)\end{array}$ & $\begin{array}{c}68 \cdot 4(7 \cdot 7) \\
107 \cdot 2(13 \cdot 7) \\
108 \cdot 1(9 \cdot 9) \\
4(0-16)\end{array}$ & $\begin{array}{l}0.025 \\
0.170 \\
0.031 \\
0.705\end{array}$ \\
\hline
\end{tabular}

WAISVIQ = Wechsler adult intelligence scale verbal IQ; NFSIQ = Full scale IQ predicted by the national adult reading test; MADRS = Montgomery-Äsberg depression rating scale; NUDS = Northwestern Universities disability scale.

Statistical analyses: age, WAISVIQ, NFSIO: Student's $t$ test;

Statistical analyses: age, WAISWO NFSIQ: Student's $t$ test;
MADRS, Hoehn and Yahr, Webster's, NUDS: Mann-Whitney U test. ${ }^{\star} \mathrm{p}<0.05$. 
Table 6 Comparison of first assessment data, according to whether or not subjects became demented (with minimum follow up of 36 months for subjects not becoming
demented)

\begin{tabular}{|c|c|c|c|}
\hline & $\begin{array}{l}P D \text { patients } \\
\text { becoming demented } \\
(n=10)\end{array}$ & $\begin{array}{l}\text { PD patients not } \\
\text { becoming demented } \\
(n=41)\end{array}$ & p Value \\
\hline $\begin{array}{l}\text { Mean (SD) age (years) } \\
\text { Sex (M:F) } \\
\text { Mean (SD) age at onset of PD (years) } \\
\text { Mean (SD) duration of PD (years) } \\
\text { Median (range) Hoehn and Yahr staging } \\
\text { Median (range) Webster's rating } \\
\text { Median (range) NUDS } \\
\text { Median (range) MADRS } \\
\text { Mean (SD) WAISVIQ } \\
\text { Mean (SD) NFSIQ } \\
\text { Median (range) MMSE }\end{array}$ & $\begin{array}{c}70 \cdot 8(3 \cdot 9) \\
9: 1 \\
60 \cdot 4(5 \cdot 1) \\
10 \cdot 0(4 \cdot 0) \\
3(2-4) \\
13(5-18) \\
39(24-48) \\
5 \cdot 5(1-16) \\
101 \cdot 1(6 \cdot 0) \\
107 \cdot 7(9 \cdot 4) \\
25(19-29)\end{array}$ & $\begin{array}{l}60 \cdot 0(9 \cdot 7) \\
24: 17 \\
55 \cdot 0(9 \cdot 3) \\
4 \cdot 9(3 \cdot 6) \\
3(1-4) \\
9(2-20) \\
44(26-50) \\
5(0-17) \\
108 \cdot 0(9 \cdot 0) \\
111 \cdot 2(8 \cdot 1) \\
29(23-30)\end{array}$ & $\begin{array}{l}<0.001 \\
\\
0.021 \\
0.003 \\
0.159 \\
0.064 \\
0.082 \\
0.830 \\
0.080 \\
0.306 \\
0.007\end{array}$ \\
\hline
\end{tabular}

NUDS = Northwestern Universities disability scale; MADRS = Montgomery-Åsberg depression rating scale; WAISVIQ = Wechsler adult intelligence scale verbal IQ; NFSIQ = Full scale IQ as predicted by the national adult reading test; MMSE = mini mental state examination.

Statistical analyses: age, age at onset of PD, duration of PD, WAISVIQ, NFSIQ: Student's $t$ test Hoehn and Yahr, Webster's, NUDS, MADRS, MMSE: Mann-Whitney U test.

spectively (although not all of our patients had a CT scan). We intend to confirm diagnosis of $P D$ at postmortem in as many of our subjects as possible.

The second issue is, how representative is the sample? The sample of PD patients was drawn from those attending local neurological outpatient clinics. Of the 89 PD patients, 69 comprised all PD sufferers from a single clinic; 18 patients were referred by five other neurologists. Such a study population may differ from the total population of PD sufferers within a community and might contain an excess of more severe or treatment resistant PD or include a greater proportion of patients with cognitive impairment. Our results are comparable with those from other studies based on outpatient samples of PD patients. At the first assessment five of our $87 \mathrm{PD}$ patients met criteria for dementia, a point prevalence of $6 \%$. The three other studies that have used DSMIII criteria have reported prevalences of dementia in PD between $11 \%$ and $15 \% .^{5-7}$ When DSM-III criteria were applied to data from seven previous hospital based studies, Lees found a range of prevalence of dementia in PD of 7-15\%; in four community based studies the range was $3-14 \% .^{7}$ Our estimate of prevalence is the lowest so far reported for a hospital based study using DSM-III criteria. There are two possible reasons for this. Firstly, the longitudinal design of our study minimises the risk of false identification of dementia due a single poor test performance. Secondly, as described in the methods section, we took particular care in applying the DSM-III criteria.

The estimate of a cumulative incidence of dementia of $19 \%$ over a 54 month follow up period in our PD cohort can be expressed in terms of number of person years of observation. We found an incidence of $47 \cdot 6 / 1000$ person years of observation. Mayeux et al estimated the incidence to be $69 / 1000$ person years of observation but used a different methodology and had an older cohort of PD patients (mean 71.4 years compared to $64 \cdot 1$ years in our study). ${ }^{10}$

Differences between subjects who withdraw and those who do not may lead to bias in the results. It is probable that some subjects refused testing because they found the procedure too arduous, possibly as a result of early cognitive impairment; we therefore suggest that such bias is likely to produce an underestimate of the frequency of occurrence of dementia. This suggestion is supported by the finding that, compared with subjects who remained in the study, those who withdrew were older and more disabled and perhaps more likely to develop dementia.

Patients who became demented during follow up already had a longer duration of $P D$ and showed a trend towards more severe PD at inclusion to the study than the $41 \mathrm{PD}$ patients who were followed for at least 36 months and did not develop dementia. This finding would be expected if the pathological processes involved in PD also contribute to the development of dementia. The finding that those PD patients who became demented were older at inclusion to the study is consistent with other recent observations that dementia is rare in young PD patients despite long duration of illness. ${ }^{25} 26$ According to a recent review, there are no clinical or neuropathological differences between young and old PD patients, ${ }^{23}$ and the rarity of dementia in young $P D$ patients suggests that the pathology of PD is in itself insufficient to cause dementia in the absence of age related factors. However, our further finding that demented patients were significantly older at the onset of the disease lends support to an alternative hypothesis that two types of PD can be distinguished on clinical grounds; patients with type 2 are said to have an older age of onset, more rapid progression, poorer response to dopaminergic agonists, and higher incidence of gait disturbance and dementia than patients with type $1 .^{27}$

Compared with those who remained free of dementia, the 10 patients who became demented during follow up had, at the first assessment, lower mean WAIS verbal IQs and lower scores on the MMSE. This suggests that although these patients did not meet the criteria for dementia at inclusion to the study they were already showing some evidence of cognitive impairment. Nineteen subjects were identified by the blind raters as meeting dementia criteria A and B, and in a further 17 (11 PD patients, six control subjects) the raters noted some cognitive impairment, although it was insufficient to meet the criteria. Further follow up may determine whether these subjects were in the early stages of dementia. Follow up of subjects is continuing and as subjects die their brains are being collected for neuropathological study.

This is the first prospective study to estimate the incidence of dementia in PD. Our finding of an incidence of $19 \%$ in 54 months is striking and contradicts suggestions, based on prevalence rates, that the risk of global dementia in patients with $\mathrm{PD}$ is only slightly greater than that in the general population. ${ }^{79}$

We thank the Parkinson's Disease Society, the Mental Health Foundation, and the Special Trustees of the United Leeds Hospitals for financial support; the Parkinson's disease patients and control subjects who took part in the study; and Alan Dabbs for assistance in rating for dementia criteria. 
1 Patrick HT, Levy DM. Parkinson's disease: a clinical study of 146 cases. Arch Neurol Psychiatry 1922;7:711-20.

2 Martin WE, Loewenson RB, Resch JA, Baker AB. Parkinson's disease. A clinical analysis of 100 patients. Neurology 1973;23:783-90.

3 Brown RG, Marsden CD. How common is dementia in Parkinson's disease? Lancet 1984;ii:1262-5.

4 American Psychiatric Association, Committee on Nomenclature and Statistics. Diagnostic and statistical manual of psychiatric disorders, third edition. Washington, DC: American Psychiatric Association, 1980

5 Mayeux R, Stern Y, Rosenstein R, Marder K, Hauser A, Cote $L$, et al. An estimate of the prevalence of dementia in idiopathic Parkinson's disease. 7 Neurol Neurosurg Psychiatry 1988;45:260-2.

6 Girotti F, Solvieri P, Carella F, Piccolo I, Caffarra P, Musicco $M$, et al. Dementia and cognitive impairment in Parkinson's disease. I Neurol Neurosurg Psychiatry 1988:51:1498-502.

7 Lees AJ. Parkinson's disease and dementia. Lancet 1985;i:43-4.

8 Taylor A, Saint-Cyr JA, Lang AE. Dementia prevalence in Parkinson's disease. Lancet 1985;ii:1037.

9 Oyebode JR, Barker WA, Blessed G, Dick DJ, Britton PG. Cognitive functioning in Parkinson's disease: in relation to prevalence of dementia and psychiatric diagnosis. $\mathrm{Br} \mathcal{J}$ Psychiatry 1986;149:720-5.

10 Mayeux R, Chen J, Mirabello E, Marder K, Bell K Dooneief G, et al. An estimate of the incidence of dementia in idiopathic Parkinson's disease. Neurology 1990;40:1513-7.

11 Hoehn MM, Yahr MD. Parkinsonism: onset, progression and mortality. Neurology 1967;17:427-42.

12 Webster D. Critical analysis of the disability in Parkinson's disease. Modern Treatment 1968;5:257-82.

13 Diamond GJ. Evaluating the evaluations: or how to weigh the scales of parkinsonism disability. Neurology 1983.33:1098-9

14 Montgomery SA, Åsberg M. A new depression rating scale designed to be sensitive to change. $\mathrm{Br} \mathcal{F}$ Psychiatry $1979 ; 134: 382-9$

15 Folstein SE, Folstein MF McHugh PR 'Mini-Mental State': a practical method for grading the cognitive state of patients for the clinician. $f$ Psychiat Res 1975; 12:189-98.

16 Wechsler D. Manual for the Wechsler adult intelligence scale. New York: Psychological Corporation, 1958

17 Wechsler D. A standardised memory scale for clinical use. $f$ Psychol 1945;19:87-95.

8 McKenna P, Warrington EK. Graded naming test manual. Windsor: NFER-Nelson, 1983

19 Nelson HE. National adult reading test manual. Windsor: NFER-Nelson, 1982.

20 Boyd JL, Cruikshank CA, Kenn CW, Madeley P, Mindham RHS, Oswald AG, et al. Cognitive impairment and dementia in Parkinson's disease: a controlled study. Psychol Med 1991;21:911-21.

21 American Psychiatric Association, Committee on Nomenclature and Statistics. Diagnostic and Statistical manual of clature and Statistics. Diagnostic and Statistical manual of mental disorders, revised third edition. Wash

22 SPSS Statistical package for the social sciences $x$. Chicago: SPSS, 1988 .

23 Gibb WRG. Dementia and Parkinson's disease. $\mathrm{Br} f$ Psychiatry 1989;154:596-614.

24 Gibb WRG, Lees AJ. The relevance of the Lewy body to the pathogenesis of idiopathic Parkinson's disease. If Neurol Neurosurg Psychiatry 1988;51:745-52.

25 Quinn NP, Critchley P, Marsden CD. Young onset Parkinson's disease. Movement Dis 1987;2:73-91.

26 Lima B, Neves G, Nora M. Juvenile parkinsonism: clinical and metabolic characteristics. F Neurol Neurosurg Psychiatry $1987 ; 50: 345-8$.

27 Godwin-Austen RB, Lowe J. The two types of Parkinson's disease. In: Rose FC, ed. Parkinson's disease: clinical and disease. In: Rose FC, ed. Parkinson's disease: clinical and
experimental advances. London: John Libbey, 1987: experiment. 